\title{
Assessment of antiretroviral therapy knowledge and willingness of persons with HIV to support its uptake in Uganda
}

This article was published in the following Dove Press journal:

Patient Preference and Adherence

7 October 2011

Number of times this article has been viewed

\author{
Richard Batamwita' \\ David M Moore ${ }^{2}$ \\ Rachel King ${ }^{3}$ \\ Edward Mills ${ }^{4}$ \\ Anne L Stangl ${ }^{5}$ \\ 'Mildmay Centre, Kampala, Uganda; \\ ${ }^{2}$ British Columbia Centre for \\ Excellence in HIVIAIDS, Vancouver, \\ Canada; ${ }^{3}$ Karolinska Institute, \\ Stockholm, Sweden; ${ }^{4}$ University \\ of Ottawa, Ottawa, Canada; \\ ${ }^{5}$ International Center for Research \\ on Women, Washington, DC, USA
}

Correspondence: Richard Batamwita Mildmay Centre, Box 24985, Kampala, Uganda

Tel +256312210200

Fax +256312210205

Email richard.batamwita@mildmay.or.ug
Background: Access to care and treatment services for human immunodeficiency virus (HIV)/ acquired immunodeficiency syndrome (AIDS) are hampered by human resource constraints and knowledge gaps about antiretroviral therapy. Training people with HIV/AIDS (PWA) as educators on antiretroviral therapy may help in the expansion of antiretroviral therapy-related knowledge in Africa. The aim of this study was to assess the antiretroviral therapy-specific knowledge, beliefs, and attitudes of PWA as well as their proactive communication with community members and to explore their willingness to serve as support personnel.

Methods: Data were obtained from a large randomized trial of PWA. We analyzed qualitative and quantitative data from 524 PWA aged 18 years and over who initiated home-based antiretroviral therapy in 2003. We assessed knowledge and communication of HIV prevention and treatment messages by PWA to communities using structured messages complemented with other knowledge questions and the willingness of PWA to serve as support persons. Descriptive bivariate associations and logistic regression statistical methods were performed. In addition, qualitative data analysis was used.

Results: The level of knowledge about antiretroviral therapy was high among all PWA on several technical attributes. Overall, 90\% of PWA reported that they had been consulted by community members for informed opinions on antiretroviral therapy, $70 \%$ felt they were opinion leaders on aspects of antiretroviral therapy within the communities, and approximately $70 \%$ were willing to be engaged as community support persons. Those who were classified as opinion leaders reported being approached more regularly by community members for expert advice about antiretroviral therapy compared with nonopinion leaders (odds ratio [OR] 11.7; 95\% confidence interval [CI] 7.3-18.6), and opinion leaders were significantly more informed on most technical attributes of antiretroviral therapy, such as "who qualifies for antiretroviral therapy based on CD4 count" (OR 1.6, 95\% CI 1.1-2.0) and "the need to be evaluated for antiretroviral therapy" (OR 1.8, 95\% CI 1.2-2.0).

Conclusion: Opinion leaders demonstrated correct knowledge and willingness to provide information on antiretroviral therapy care and treatment issues and were, in turn, consulted more frequently for antiretroviral therapy advice compared with nonopinion leaders. Training opinion leaders to work as community support personnel may increase knowledge about antiretroviral therapy in underserved communities.

Keywords: opinion leaders, antiretroviral therapy, knowledge, proactive communication, Uganda, human immunodeficiency virus

\section{Introduction}

The World Health Organization (WHO) has recently provided guidance on taskshifting approaches to address human resource shortages in health, particularly for 
less developed regions. It is anticipated that some of the less demanding community-based tasks regarding human immunodeficiency virus (HIV)/acquired immunodeficiency syndrome (AIDS) management can be shifted to people with HIV/AIDS (PWA). ${ }^{1}$

HIV/AIDS rates in Uganda are still relatively high. In 2009 , the prevalence rate was $6.4 \%$ in the age group 15-49 years, translating into approximately 1.1 million people. HIV/AIDS in Uganda is categorized as a generalized epidemic. However, knowledge about antiretroviral therapy has remained low, at about $35 \%$ in this same age group. This inadequate knowledge possibly translates into low uptake of vital services, such as voluntary counseling, testing, and care and support services. Voluntary counseling and testing is an entry point into treatment and care services, but only about $12 \%$ Ugandans seek it out. ${ }^{2}$ As of 2010 , approximately 140,000 people in Uganda are receiving antiretroviral therapy. ${ }^{3}$ The low knowledge about antiretroviral therapy coupled with scarcity of the human resources necessary for promotion and sustenance of antiretroviral therapy programs are one of several reasons for low uptake of antiretroviral therapy programs. One strategy to address the low supply of human resources for HIV health services, especially in less developed countries, is the utilization of PWA as community support persons. This strategy is being proposed as a key to address general health worker shortages. ${ }^{1}$

The advent and scale-up of antiretroviral therapy has drastically reduced opportunistic infections and subsequent deaths. ${ }^{4}$ However, as antiretroviral therapy programs rapidly expand in resource-constrained settings, increasing access to information about antiretroviral therapy becomes imperative. Africa remains critically short of health workers, who are central in the provision of antiretroviral therapy programs. ${ }^{5-7}$ Pilot projects in Africa have shown that the development of community-based antiretroviral therapy treatment support persons can lead to high treatment literacy, improve adherence rates, and other multiple positive social outcomes. ${ }^{8,9}$ Countries most affected by AIDS could appropriately develop a new cadre of health workers suitable to provide HIV-related services. ${ }^{10}$

The use of community support persons to disseminate information about HIV/AIDS prevention and related treatment services could assist in improving antiretroviral therapy treatment literacy. ${ }^{11}$ A recent study in Uganda suggested that reassigning the work of monitoring and patient support to PWA could leave medical personnel free to handle clinical tasks. ${ }^{12}$ In line with the World Health Organization recommendations on task shifting, PWA, ${ }^{1,13}$ who are regularly exposed to valuable HIV/AIDS and antiretroviral therapy information from clinic and project staff and have varied treatment experiences, could add value to community-based approaches to HIV prevention and treatment. Their information and experiences could be shared with community members, both HIV-positive and HIV-negative, and might help to mitigate barriers to access and utilization of HIV/ AIDS services as well as lessening stigma and discrimination. ${ }^{7}$ PWA have been involved in the response against HIV/ AIDS since the first phases of the epidemic,,$^{5}$ and public health agencies recognize that their participation should continue to be actively encouraged. ${ }^{14,15}$

Despite this recognition, there has been little effort in assessing how PWA function in providing community support to antiretroviral therapy programs, particularly the type, frequency, and accuracy of information, and their attitudes and beliefs about antiretroviral therapy which they portray to community members. Our objective was to assess the specific knowledge, beliefs, and attitudes of PWA about antiretroviral therapy, as well as proactive communication about HIV/AIDS and antiretroviral therapy. We also set out to determine the proportion of PWA who were willing to be engaged as community support persons. A greater understanding of these factors could inform systematic efforts to utilize PWA effectively in prevention, treatment, care, and support programs in communities where human resources for health are in short supply.

\section{Methods}

We collected cross-sectional data between July 2005 and December 2005 as part of a large randomized control trial of 1000 HIV-positive persons, aged 18 years and over, who initiated home-based antiretroviral therapy between May 2003 and November 2006. The trial was called the Home-Based AIDS Care project (HBAC), facilitated by a study clinic at Tororo District Hospital in Eastern Uganda. This study was approved by the Uganda National Council for Science and Technology, the Uganda Virus Science and Ethics Committee, and the Centers for Disease Control and Prevention.

\section{Participant enrollment into the HBAC}

All participants who were recruited into HBAC were seropositive for HIV. The HBAC was supported by the US President's Emergency Plan for AIDS Relief, and managed jointly by the Centers for Disease Control and Prevention in collaboration with the Uganda Ministry of Health and local government districts of Tororo, Busia, and Mbale. Recruitment into the trial started in May 2003 and continued through 
November 2006. All the participants recruited into the HBAC were previously members of another HIV/AIDS organization called The AIDS Support Organization (TASO), which they had joined at varying times starting in the mid 1990s. Details of the HBAC trial are described elsewhere. ${ }^{16,17}$

\section{Sample selection}

From the HBAC project, a quota sample of 524 participants was selected who had initiated antiretroviral therapy with a CD4 count of $\leq 250$ cells $/ \mu \mathrm{L}$ or with symptomatic AIDS, and lived within a $100 \mathrm{~km}$ radius of the clinic, aged 18 years or older, and had been receiving antiretroviral therapy and routine counseling for at least 18 months within the HBAC project.

\section{Data collection}

Research counselors were given training in specific methods for collecting sensitive information from PWA for a period of 1 month. Between July 2005 and December 2005, the counselors collected data from randomly selected eligible clients using a structured questionnaire that assessed HIV/ AIDS, antiretroviral therapy knowledge and misconceptions, and HIV-related communication and opinion leadership (an opinion leader was defined as a PWA who self-reported to be an expert on HIV/AIDS and antiretroviral therapy-related information within the community).

To assess knowledge and misconceptions about antiretroviral therapy for HIV/AIDS, five key thematic questions were asked using yes/no and multiple choice response options. To assess whether specific HIV/AIDS and antiretroviral therapy-related information were communicated by PWA, 22 typical messages were asked. We asked PWA what they typically told a community member about HIV/ AIDS or antiretroviral therapy. These questions were asked without prompting, and any mentioned response was marked off the list of 22. The 22 questions used were derived from conventional counseling messages in Uganda. ${ }^{18}$ Research counselors also collected demographic and screening information at baseline and at 6-monthly follow-up intervals up to 18 months. The counselors had also provided routine voluntary counseling services on HIV/AIDS preventive and treatment-seeking behavior, positive living, and antiretroviral therapy adherence. PWA who self-reported to be experts on HIV/AIDS and antiretroviral therapy and community members consulted on HIV/AIDS/antiretroviral therapy-related information and advice were classified as opinion leaders and the rest were classified as nonopinion leaders. All quantitative data were double-entered using
Epi-Info 2002 (Centers for Disease Control and Prevention, Atlanta, GA).

To complement quantitative data and triangulate information, this study used some key qualitative data from the main HBAC study, which had a qualitative data component. These data had been gathered routinely by behavioral research scientists. The data covered a range of issues related to antiretroviral therapy, including knowledge, attitudes, behavior, and practices of PWA. Qualitative data were entered in Nvivo2 (QSR International Pty Ltd, Victoria, Australia). A thematic codebook was developed, and specific content line segments were coded at nodes and later extracted at analysis.

\section{Data analysis}

For the quantitative portion of our study, we first used descriptive statistics for all sociodemographic variables to assess their distribution. Second, antiretroviral therapy knowledge, attitudes, beliefs, social status changes, sources of antiretroviral therapy information, changes in proactive communication by PWA about antiretroviral therapy, travel frequency, reported consultation of PWA by community members, opinion leadership, antiretroviral therapy messages communicated, and willingness to participate as community support persons were tabulated. Third, we classified PWA as opinion leaders or nonopinion leaders, and Chi-square tests were conducted along with unadjusted odds ratios (OR) and confidence intervals (CI) to assess differences in levels of communication and knowledge about antiretroviral therapy between opinion leaders or nonopinion leaders. We stratified by gender, marital status, education, reported consultation of PWA by community members, reported social status changes, and travel frequency of the PWA to assess for any significant differences. All quantitative analyses were conducted using SAS version 9.1 (SAS Institute, Cary, NC).

For qualitative data, we aimed to seek a more detailed understanding of the participants' beliefs and attitudes about HIV and antiretroviral therapy, as well as how PWA have been sharing their treatment experiences within the communities. Some of the specific content areas identified were how PWA managed their disease condition, including overcoming stigma, community attitudes towards PWA, current social status and roles, and indepth knowledge of antiretroviral therapy. We also explored the willingness of PWA to participate in the proposed projects as community educators (Table 2). Qualitative data were analyzed in Nvivo2. 


\section{Results}

\section{Participant characteristics}

A total of 987 adult clients ( $74 \%$ female) initiated antiretroviral therapy from May 2003 through December 2006 in the main randomized trial, and 524 (71\% female) who had completed 18 months of follow-up were enrolled in this substudy. Of the 524 PWA, 371 (71\%) were females and $210(40 \%)$ had completed primary education, with significant differences between the two gender groups (22\% female versus $38 \%$ male, $P<0.01)$. Overall, $232(45 \%)$ were married and there were more married males compared with females ( $80 \%$ versus $30 \%$, respectively, OR 9, 95\%, CI 5.7-14.3, $P<0.01$.). The median age at enrollment was 38 years (interquartile range $31-42$ years) for females and 41 years (interquartile range 34-47 years) for males. As shown in Table 1, most PWA were Catholics 221 (45\%) or Protestants (35\%).

Table I Sociodemographic and background attributes of PWA after 18 months on antiretroviral therapy, Home-Based AIDS Care project, 2005

\begin{tabular}{|c|c|c|c|}
\hline \multirow[t]{2}{*}{ Background variables } & All n (\%) & Female n (\%) & Male n (\%) \\
\hline & $524(100)$ & $373(\%)$ & I5I (\%) \\
\hline None & $128(25)$ & $113(3 \mathrm{I})$ & $15(10)$ \\
\hline Primary & $248(48)$ & I7| (47) & $77(52)$ \\
\hline Postprimary & 137 (27) & $82(22)$ & $55(38)$ \\
\hline Catholic & $221(42)$ & $155(42)$ & $66(44)$ \\
\hline Moslem & $42(8)$ & $25(7)$ & $17(11)$ \\
\hline Pentecostal & $80(15)$ & $57(15)$ & $21(14)$ \\
\hline Protestant & $18 \mid(35)$ & $134(36)$ & $47(3 \mathrm{I})$ \\
\hline \multicolumn{4}{|l|}{ Marital status } \\
\hline Married & $232(45)$ & II3 (30) & $119(80)$ \\
\hline Not married & $287(55)$ & $257(70)$ & $30(20)$ \\
\hline $18-30$ & $54(10)$ & $45(12)$ & $9(6)$ \\
\hline $31-40$ & $216(4 I)$ & $162(43)$ & $54(36)$ \\
\hline $4 I-50$ & $188(36)$ & $130(35)$ & $58(38)$ \\
\hline $50+$ & $66(13)$ & $36(10)$ & $30(20)$ \\
\hline At least once per week & $159(30)$ & $94(25)$ & $65(43)$ \\
\hline Once a month & $10(2 I)$ & $74(20)$ & $36(24)$ \\
\hline Rarely & $254(49)$ & $204(55)$ & $50(33)$ \\
\hline Improved & $4 \mid 3(8 I)$ & $287(78)$ & $126(85)$ \\
\hline Stayed same & $98(19)$ & $83(22)$ & $23(15)$ \\
\hline $\begin{array}{l}\text { Daily/several times } \\
\text { per week }\end{array}$ & III (2I) & $65(18)$ & $46(3 I)$ \\
\hline Once per week & $69(13)$ & $49(13)$ & $20(13)$ \\
\hline Occasionally & $295(57)$ & $218(59)$ & $77(5 \mathrm{I})$ \\
\hline Never & $45(9)$ & $38(10)$ & $7(5)$ \\
\hline Farming & 203 (39) & $|4|$ (38) & $62(44)$ \\
\hline Wages & $77(16)$ & $50(14)$ & $27(19)$ \\
\hline Dependent & $91(18)$ & $80(22)$ & II (8) \\
\hline Trade & $136(26)$ & $95(26)$ & $4 \mid(29)$ \\
\hline
\end{tabular}

Abbreviations: $n$, number; AIDS, acquired immunodeficiency syndrome; PWA, people with human immunodeficiency virus/AIDS.

\section{Social status change among PWA since initiation of antiretroviral therapy}

After 18 months on antiretroviral therapy, all participants reported improvements in social status that included increased social interactions, more prominent roles in the community, influence of PWA in the community, and/or positive community views of PWA. Social status increased greatly among both males $(85 \%)$ and females (78\%), but the gender difference was not statistically different $(P=0.07)$. However, opinion leaders reported better improvement than nonopinion leaders (OR 5.0, 95\% CI 3.3-8.0, $P<0.001)$

\section{Sources of information about antiretroviral therapy}

The main sources of information about antiretroviral therapy for all PWA were HBAC study counselors (81\%), field officers (65\%), and radio (43\%). About 19\% said that they heard about antiretroviral therapy from fellow PWA who were registered members with the HBAC project.

\section{Level of antiretroviral therapy knowledge}

Most PWA exhibited high levels of knowledge and understanding of antiretroviral therapy issues (Table 2). Responses to the two questions, "What do antiretrovirals do?" and "When should one start antiretrovirals?" were answered correctly by the majority of PWA. For instance, $443(85 \%)$ spontaneously mentioned that antiretroviral therapy improves health and immune system functioning. Similarly, a relatively large proportion of PWA, ie, 386 (74\%) clearly expressed that an HIV-positive person needs to start antiretroviral therapy when the CD4 count is less than $\leq 250$ cells $/ \mu \mathrm{L}$. Additionally, $241(46 \%)$ replied that antiretroviral therapy prolongs the life of PWA and 217 (41\%) said antiretroviral therapy reduces opportunistic infections. Incorrect information about antiretroviral therapy was mentioned by a small proportion, such as those who answered positively that antiretroviral therapy kills HIV (17 [3\%]) and cures AIDS (23 [4\%]). The median number of correct answers about antiretroviral therapy was three, and at least $31 \%$ mentioned more than four answers correctly.

The qualitative data corroborated the evidence that PWA are knowledgeable about antiretroviral therapy and they shared extensive stories about attributes related to drug functions. For instance, they mentioned drugs such as Septrin $^{\circledR}$ (cotrimoxazole, a drug for opportunistic infections in all PWA, regardless of CD4 cell count $/ \mu \mathrm{L}) .{ }^{19,20}$ Similarly, 
Table 2 Percentage of responses by people with HIVIAIDS to two antiretroviral knowledge questions after 18 months on antiretroviral therapy, Home-Based AIDS Care project, $2005(n=524)^{*}$

\begin{tabular}{ll}
\hline Specific knowledge about & Responses (\%) \\
antiretroviral therapy & \\
\hline Answers to question: What do ARV drugs do? & \\
Kills HIV & 3 \\
Increases sickness & $\mathrm{I}$ \\
Cures AIDS & 4 \\
Improves health/strength/immune system & 85 \\
Slows the progression of HIV & 44 \\
Reduces opportunistic infections & $4 \mathrm{I}$ \\
Increases CD4 count & 38 \\
Decreases the level of virus in the body & 42 \\
Prolongs life of PWA & 46 \\
Kills people & $\mathrm{I}$ \\
Don't know & $\mathrm{I}$ \\
Causes bad side effects & 6 \\
Answers to question: When should a person with HIV/AIDS start ARV? \\
When they are physically sick & $\mathrm{II}$ \\
As soon as they test positive & $\mathrm{I}$ \\
When they are too weak to continue their & I2 \\
daily activities & \\
When their CD4 count is $<250$ & 74 \\
Don't know & $\mathrm{I}$ \\
Not all HIV-positive people need ARV & 78 \\
After improvement on antiretroviral therapy & 93 \\
one should continue &
\end{tabular}

Note: *The responses were spontaneous.

Abbreviations: ARV, antiretroviral therapy; AIDS, acquired immunodeficiency syndrome; HIV, human immunodeficiency virus; PWA, people with HIVIAIDS.

they mentioned clean water and other antiretroviral agents. Clean water use is mentioned here because previous deaths of most PWA in this area were associated with dirty water that resulted in diarrhea-related diseases. ${ }^{21}$

\section{Beliefs about antiretroviral therapy}

The participants were asked whether they felt that their feelings and thoughts had changed after starting antiretroviral therapy. The most striking beliefs were those related to hopes of living longer (78\%), feeling of being healthy with less illness (62\%), and reduction in worries and fear (42\%).

The qualitative data revealed that PWA perceived community members as having some false beliefs about the health of HIV-positive individuals and, in some cases, the role of antiretroviral therapy in particular. For instance, some PWA revealed that when their health improved, such as gaining of weight and reduction in opportunistic infections, ${ }^{21,22} \mathrm{com}$ munity members started wondering whether these PWA actually had AIDS.

\section{Type and frequency of information about antiretroviral therapy}

Generally, the most frequently provided message was about who qualifies for antiretroviral therapy followed by the need to register with an AIDS service organization and the role of antiretroviral therapy with respect to prolonging the life of PWA. These results are summarized in Table 3.

Overall, 408 (78\%) PWA reported having provided information to community members since enrolling in the HBAC. However, the frequency with which they communicated about HIV/antiretroviral therapy varied, with 111 (21\%) responding that they provided information every day, $69(13 \%)$ responding once a week, the majority saying occasionally (95 [56\%]), and $45(9 \%)$ saying never. There was also an increase in the proportion of individuals who said they ever communicated about HIV/AIDS, testing, serostatus,

Table 3 Antiretroviral therapy messages communicated to community members by people with HIVIAIDS, comparing opinion leaders with nonopinion leaders

\begin{tabular}{|c|c|c|c|c|}
\hline $\begin{array}{l}\text { ARV messages } \\
\text { communicated }\end{array}$ & $\begin{array}{l}\text { OPLs } \\
n=370 \\
n(\%)\end{array}$ & $\begin{array}{l}\text { Non-OPLs } \\
n=152 \\
n(\%)\end{array}$ & $P$ value & OR \\
\hline $\begin{array}{l}A R V \text { is for those } \\
\text { with CD4 }<250\end{array}$ & $192(5 \mathrm{I})$ & $61(40)$ & 0.019 & $1.6(1.1-2.4)$ \\
\hline $\begin{array}{l}\text { You need an HIV } \\
\text { test before ARV }\end{array}$ & I89 (5।) & $54(36)$ & 0.002 & $1.9(1.3-2.8)$ \\
\hline $\begin{array}{l}\text { ARV prolongs } \\
\text { your life }\end{array}$ & $42(\mathrm{II})$ & $6(4)$ & 0.679 & $0.9(0.6-1.3)$ \\
\hline $\begin{array}{l}\text { Need to register } \\
\text { with an AIDS } \\
\text { service facility } \\
\text { to access ARV }\end{array}$ & $194(52)$ & $55(36)$ & 0.001 & $1.9(1.3-2.9)$ \\
\hline $\begin{array}{l}\text { You need to be } \\
\text { evaluated for ARV }\end{array}$ & I44 (39) & $40(26)$ & 0.008 & $1.8(1.2-2.7)$ \\
\hline $\begin{array}{l}\text { Adherence to ARV } \\
\text { is important }\end{array}$ & $82(22)$ & $31(20)$ & 0.743 & I.I (0.7-I.8) \\
\hline $\begin{array}{l}\text { Not everyone } \\
\text { with HIV needs } \\
\text { antiretroviral } \\
\text { therapy }\end{array}$ & $68(18)$ & $19(12)$ & 0.135 & I.6 (0.9-2.7) \\
\hline $\begin{array}{l}\text { ARV should not be } \\
\text { shared with others }\end{array}$ & $64(17)$ & $20(13)$ & 0.299 & I.4 (0.8-2.4) \\
\hline $\begin{array}{l}\text { ARV does not cure } \\
\text { HIVIAIDS }\end{array}$ & $75(20)$ & $42(28)$ & 0.086 & $0.7(0.4-1.0)$ \\
\hline $\begin{array}{l}\text { While on ARV, you } \\
\text { remain infectious } \\
\text { if you don't use } \\
\text { condoms }\end{array}$ & $53(14)$ & $13(9)$ & 0.097 & $1.8(0.9-3.4)$ \\
\hline $\begin{array}{l}\text { Once on ARV, you } \\
\text { take it for life }\end{array}$ & $58(16)$ & $31(20)$ & 0.240 & $0.7(0.4-1.2)$ \\
\hline
\end{tabular}

Abbreviations: ARV, antiretroviral therapy; AIDS, acquired immunodeficiency syndrome; HIV, human immunodeficiency virus; PWA, people with HIVIAIDS; OPLs, opinion leaders; non-OPLs, nonopinion leaders; OR, odds ratio. 
or antiretroviral therapy from the time they joined HBAC, from $267(51 \%)$ to $408(78 \%)$. Results show that females reported that they provided antiretroviral therapy information on a daily basis less frequently than males ( $18 \%$ of females versus $31 \%$ of males, $P<0.001$ ).

The qualitative analysis revealed some critical issues which the community members usually discussed with respect to PWA. They included lack of fear of HIV, men's desire for children even when they are sick, and aspects of prevention of mother to child transmission of HIV. Other community members simply believe that when PWA produce children, they are actually spreading the virus.

\section{Self-reported opinion leadership}

Overall, there were more opinion leaders (370 [71\%]), ie, those who self-reported to be leaders in aspects of HIV/ AIDS and antiretroviral therapy, than nonopinion leaders. Significant differences were observed by education. Close to $30 \%$ of the opinion leaders had postprimary education compared with $17 \%$ of the nonopinion leaders $(P<0.001)$. There was no significant difference between the groups with respect to marital status, gender, and religion. The opinion leaders were consulted by the community members for advice more often than the nonopinion leaders ( $72 \%$ versus $18 \%$, OR 11.7, CI 7.3-18.6).

\section{Community member consultations with PWA about antiretroviral therapy}

We asked all PWA whether community members consulted them for antiretroviral therapy-specific advice. We used this as another variable to assess if PWA are opinion leaders in their community. We compared the response about consultation by the community and previously self-reported opinion leadership. Among those who self-reported to be opinion leaders, $71 \%$ reported being consulted by the community whereas among those who self-reported to be nonopinion leaders, only $18 \%$ were consulted.

\section{Discussion}

We found a relatively high specific knowledge level about HIV/AIDS and antiretroviral therapy and PWA engagement in proactive information-sharing. There is evidence of informal networks emerging where community members consult PWA for information and advice in general about HIV/AIDS and in particular about antiretroviral therapy. In antiretroviral therapy program management, accurate knowledge and timely information that facilitates antiretroviral therapy uptake is crucial. ${ }^{24-26}$ Shared information between
PWA and community members could positively influence HIV-positive community members to seek treatment and care services which will in turn lead to uptake of antiretroviral therapy. Likewise, community members who have never taken an HIV test could be influenced to seek one and benefit from prevention counseling or join AIDS service facilities if they are found to be HIV-positive. We maintain that formal arrangements to engage PWA as community-based support personnel should be undertaken urgently. This is based on the findings that the PWA are quite knowledgeable, more familiar with community members, and are already executing these information-sharing tasks in an informal manner.

The PWA reported positive beliefs, indicating self-efficacy, a wish to live longer, positive changes in social status, and a willingness to speak out and influence others. This could mean that PWA are gradually overcoming the stigma that in the past was a major obstacle to HIV/AIDS services in Uganda. ${ }^{27}$ The stigma has been so strong that, in the initial phases of the HBAC program, community members tried to dissociate themselves from homes which were being visited by the program motorcycles during follow-up and drug delivery. Because stigma is one of the biggest obstacles to voluntary counseling, testing uptake, and antiretroviral therapy initiation, ${ }^{28}$ PWA could play a more important role in influencing community members given their experience, level of familiarity, and success stories. Similarly, because the stigma is decreasing, PWA will hopefully meet limited resistance from community members and would be able to execute their assigned tasks.

There are many emotional and psychological challenges surrounding proper communication about HIV/AIDS due to its life-threatening nature. ${ }^{29}$ PWA taking antiretroviral therapy could use their treatment experiences to help other community members overcome obstacles to care and treatment. These could include helping newly diagnosed community members disclose their status to partners and children, guiding them to appropriate treatment centers, counseling them to adhere to antiretroviral therapy, and providing them with an enabling environment to cope with the disease.

In recent times, the limitations of clinic-based services have become more apparent and there is a growing realization and acknowledgment of the appropriateness (accessiblity, linkages, coverage, and acceptability) of involving community-based health workers to meet the health needs of populations, especially in resource-poor regions. ${ }^{30}$ We suggest formal involvement of PWA to serve as links between antiretroviral therapy facilities and communities. Both in this analysis and in the literature there is strong evidence that PWA are willing to undertake these tasks. ${ }^{31}$ 
Although opinion leaders and nonopinion leaders in this study were quite different in several demographic characteristics, they differed slightly in only four aspects of communicating antiretroviral therapy messages, and both groups reported being approached by community members for informed opinion on matters of antiretroviral therapy. However, the self-reported opinion leaders were more frequently approached than the nonopinion leaders. In the four technical aspects where both groups differed, the opinion leaders were more accurate on specific messages than nonopinion leaders. This suggests that antiretroviral therapy programs should formally target those PWA who self-report to be opinion leaders. Upon identifying these individuals, regular support (technical and support supervision) may be planned and executed to reinforce their subject content.

Although our study undertook critical methodological steps in the design, implementation, and analysis stages, it was not able to circumvent completely the usual limitations related to self-reported data. In this study, all the responses were selfreported. Self-reporting has been shown to lead to social desirability bias. ${ }^{32}$ To determine adequately if community members consult PWA, rather than relying solely on self-reported information from PWA, a community-based study using qualitative and quantitative methods involving only HIV-negative persons would have possibly confirmed the frequency and level of consultation with PWA by community members.

We minimized knowledge-related reporting bias by asking several core antiretroviral therapy questions relating to knowledge, beliefs, attitudes, willing to participate, and opinion leadership using nonprompting techniques, ie, asking for answers spontaneously. We also recruited experienced research counselors to collect detailed sensitive information. Additionally, a qualitative methodology was also adopted in order to triangulate the collected information. Neither the quantitative nor the qualitative findings varied greatly. Given that most of the PWA in this study had lived with the disease for long periods, ie, a minimum of nine years, we are confident that their knowledge about antiretroviral therapy had also progressively improved due to exposure to the educational messages received.

Moreover, the study population may not be representative, given that all the PWA had engaged in HIV-related programs for many years, because they were initially members of TASO, an organization which has operated for nearly two decades. Their previous participation in TASO might have significantly improved their antiretroviral therapy knowledge, and changed their attitudes as well as beliefs. Therefore, generalization of these results to other rural settings may require some modifications for suitability and context. However, in rural communities where TASO and other related HIV/AIDS service organization operate and offer similar services, the transferability of these findings would be appropriate.

Lastly, this analysis was not able to determine factors that caused PWA to have particular knowledge of antiretroviral therapy, beliefs, attitudes, or willingness to serve as community support persons due to the limitations of cross-sectional data. In other words, although the main study was a controlled trial, this particular study used cross-sectional data. A combination of many factors, notwithstanding their previous membership in TASO, followed by enrollment in HBAC, might have played a significant role in shaping their current readiness to become community educators. We also acknowledge that the data are relatively old, given the time period during which the project was implemented (2003-2006). However, this important area of HIV research has not been sufficiently studied in Uganda.

\section{Conclusion}

Despite these limitations, our findings are timely in that they provide comprehensive information to PWA regarding current antiretroviral therapy knowledge, proactive communication, and consultation with community members about HIV and antiretroviral therapy. In addition, they reveal the willingness of PWA to serve as community support personnel in current efforts to expand antiretroviral therapy programs in resource-poor countries. Appropriate integration of PWA in antiretroviral therapy programs in rural Africa, particularly Uganda, would serve as a beneficial strategy to improve HIV treatment, health-seeking behaviors, uptake of antiretroviral therapy services, and provide strategies for responding to the critical issues of human health care resources in the struggle against HIV/AIDS.

\section{Acknowledgments}

We thank the HBAC participants who voluntarily agreed to be interviewed for this study. We also thank the fieldbased HBAC staff, in particular, Ezati Enoch and Bechange Stevens. The HBAC program was funded by the US Centers for Disease Control and Prevention through the Presidents Emergency Plan for AIDS relief.

\section{Disclosure}

The authors report no conflicts of interest in this work.

\section{References}

1. WHO/PEPFAR/UNAIDS. Task shifting. Global recommendations and guidelines. 2007. Available from: http://whqlibdoc.who.int/ unaids/2007/9789241596312_eng.pdf. Accessed November 25, 2010. 
2. Ministry of Health Kampala, Uganda and ORC Macro. Uganda HIV/ AIDS serobehavioural survey 2004-2005. Calverton, MD: Ministry of Health Kampala, Uganda and ORC Macro; 2006.

3. President's Emergency Plan for AIDS Relief. Uganda fiscal year 2008 country PEPFAR operational plan. 2008. Available from: http://www. pepfar.gov/about/opplan08/102010.htm. Accessed June 16, 2009.

4. Joint United Nations Programme on HIV/AIDS and World Health Organization. AIDS epidemic update. Available from: http://data. unaids.org/pub/EPISlides/2007. Accessed July 8, 2009.

5. Joint United Nations Programme on HIV/AIDS. Report on the global HIV/AIDS epidemic. 4th global report. 2004. Available from: http:// www.unaids.org/bangkok2004/GAR2004_pdf/UNAIDSGlobalRe port2004_en.pdf. Accessed May 1, 2009.

6. Kober K, Van DW. Scaling up access to antiretroviral treatment in southern Africa: Who will do the job? Lancet. 2004;364:103-107.

7. Grubb I, Perriens J, Schwartlander B. A Public Health Approach to Antiretroviral Treatment. Overcoming Constraints. Geneva, Switzerland: World Health Organization; 2003.

8. Schneider H, Coetzee D. Strengthening the health system and ensuring equity in the widescale implementation of an antiretroviral therapy programme in South Africa. S Afr Med J. 2003;93:772-773.

9. Apondi R, Bunnell B, Awor A, et al. Home-based antiretroviral care is associated with positive social outcomes in a prospective cohort in Uganda. Immune Defic Syndr. 2007;44:71-76.

10. Badara S, Francesca C. Expansion of the Health Workforce and the HIV Epidemic. Geneva: World Health Organization; 2007.

11. Joint United Nations Programme on HIV/AIDS. Intensifying HIV Prevention: UNAIDS Policy Position Paper. Geneva: Joint United Nations Programme on HIV/AIDS; 2005.

12. Chang LW, Kagaayi J, Nakigozi G, et al. Responding to the human resource crisis: Peer health workers, mobile phones, and HIV care in Rakai, Uganda. AIDS Patient Care STDS. 2008;22:173-174.

13. Joint United Nations Programme on HIV/AIDS. Scaling up Access to HIV Prevention, Treatment, Care and Support. The Next Steps. Geneva, Switzerland: Joint United Nations Programme on HIV/AIDS; 2006.

14. Joint United Nations Programme on HIV/AIDS. From Principle to Practice. Greater Involvement of People Living with or Affected by HIV/AIDS. Geneva: Joint United Nations Programme on HIV/AIDS; 1999.

15. Centers for Disease Control and Prevention. Incorporating HIV prevention into the medical care of persons living with HIV. Recommendations of CDC, the Health Resources and Services Administration, the National Institutes of Health, and the HIV Medicine Association of the Infectious Diseases Society of America. MMWR Recomm Rep. 2003;52:1-24.

16. Bunnell R, Ekwaru JP, Solberg P, et al. Changes in sexual behavior and risk of HIV transmission after antiretroviral therapy and prevention interventions in rural Uganda. AIDS. 2006;20:85-92.

17. Weidle PJ, Wamai N, Solberg P, et al. Adherence to antiretroviral therapy in a home-based AIDS care programme in rural Uganda. Lancet. 2006;368:1587-1594.
18. Ministry of Health. National HIV Counseling and Testing Training Manual. Kampala: Ministry of Health; 2005.

19. Uganda Ministry of Health. National Antiretroviral Treatment And Care Guidelines for Adults and Children. 2008. Available from http:// collections.infocollections.org/whocountry/en/d/Jh4325e/.

20. Joint United Nations Programme on HIV/AIDS. Facts about HIV/ Prevention. 2008. Available from: http://data.unaids.org/pub/ BaseDocument/2008/20080501_fastfacts_prevention_en.pdf. Accessed June 20, 2010.

21. Lule J, Mermin J, Ekwaru P, et al. Effect of home-based water chlorination and safe storage on diarrhea among persons with human immunodeficiency virus in Uganda. Am J Trop Med Hyg. 2005;73:926-933.

22. Weidle P, Malamba S, Mwebaze R, Sozi C, Rukundo G, Downing R. Assessment of a pilot antiretroviral drug therapy programme in Uganda: Patients' response, survival, and drug resistance. Lancet. 2002;360: 34-40

23. International Center for Research on Women. HIV AIDS stigma: Funding solutions to strengthen HIV Programs. 2009. Available from: http://www.icrw.org/docs/2006_stigmasynthesis.pdf. Accessed July 28, 2009.

24. Zolopa AR, Andersen J, Komarow L, et al. Early antiretroviral therapy reduces AIDS progression/death in individuals with acute opportunistic infections: A multicenter randomized strategy trial. PLoS One. 2009;4: e5575.

25. Liechty CA. The evolving role of HIV counseling and testing in resource-limited settings: HIV prevention and linkage to expanding HIV care access. Curr HIV/AIDS Rep. 2004;1:181-185.

26. Granich RM, Gilks CF, Dye C, De Cock KM, Williams BG. Universal voluntary HIV testing with immediate antiretroviral therapy as a strategy for elimination of HIV transmission. A mathematical model. Lancet. 2009;373:48-57.

27. Matovu1 KB, Makumbi E. Expanding access to voluntary HIV counseling and testing in sub-Saharan Africa: Alternative approaches for improving uptake. Trop Med Int Health. 2007;12:1315-1322.

28. Bwambale M, Ssali N, Byaruhanga S. Voluntary HIV counselling and testing among men in rural western Uganda: Implications for HIV prevention. 2008. Available from: http://www.biomedcentral. com/1471-2458/8/263. Accessed June 15, 2009.

29. Wiener L, Mellins CA, Marhefka S, Battles HB. Disclosure of an HIV diagnosis to children: History, current research, and future directions. J Dev Behav Pediatr. 2007;28:155-166.

30. Joint United Nations Programme on HIV/AIDS. From principle to practice: Greater involvement of people living with or affected by HIV/ AIDS. 1999. Available from :http://www.unaids.org/en/PolicyAndPractice/GIPA/default.asp. Accessed June 15, 2009.

31. Morolake O, Stephens D, Welbourn A. Greater involvement of people living with HIV in health care. 2009. Available from: http://www. jiasociety.org/content/12/1/4. Accessed July 30, 2011.

32. Schroeder E, Carey P, Vanable A. Methodological challenges in research on sexual risk behavior: II. Accuracy of self-reports. Ann Behav Med. 2003;26:104-123.
Patient Preference and Adherence

\section{Publish your work in this journal}

Patient Preference and Adherence is an international, peer-reviewed, open access journal focusing on the growing importance of patient preference and adherence throughout the therapeutic continuum. Patient satisfaction, acceptability, quality of life, compliance, persistence and their role in developing new therapeutic modalities and compounds to

\section{Dovepress}

optimize clinical outcomes for existing disease states are major areas of interest. This journal has been accepted for indexing on PubMed Central. The manuscript management system is completely online and includes a very quick and fair peer-review system. Visit http://www.dovepress.com/ testimonials.php to read real quotes from published authors. 